\title{
Flame Photometry
}

National Cancer Institute

\section{Source}

National Cancer Institute. Flame Photometry. NCI Thesaurus. Code C106523.

A type of atomic spectroscopy capable of qualitatively or quantitatively determining certain cations (particularly $\mathrm{Na}, \mathrm{K}, \mathrm{Rb}, \mathrm{Cs}, \mathrm{Ca}, \mathrm{Ba}, \mathrm{Cu}$ ) by utilizing a low temperature flame capable of exciting a valence electron to an upper energy state which emits light at a waveleng th unique to each cation as the electron returns to its ground state. 